MATEC Web of Conferences 22,02032 (2015)

DOI: $10.1051 /$ matec conf/ 20152202032

(C) Owned by the authors, published by EDP Sciences, 2015

\title{
Optimum Design for Slot-type of Stator Based on PM Motor with Hal- bach Structure
}

\author{
Yongxin Zhu* \& Mingzhong Qiao \\ College of Electric Engineering, Naval University of Engineering, Wuhan, Hubei, China
}

\begin{abstract}
The performance of permanent magnet motor is directly influenced by the PM structure of rotor and the slot type of stator. An emerging rotor magnetization type of PM motor is Halbach structure, which has obvious advantages in comparison to ordinary permanent structures and in application, especially in the design of propeller integration system. Commonly, Halbach array is used in discrete permanent magnet structure on the rotor of machine. On the stator, air gap flux density varies as the slot type changes, and complex slot types will bring about complex air gap equivalent process of the motor, which will influence the procedures of simulation calculation and experiments. According to the characteristics of Halbach array, the intensifying effect of the Halbach array on magnetic flux density of air gap is analyzed in this paper, and the electromagnetic field of PM motor is calculated. By using FEM method, the magnetic flux density of air gap, back phase electromotive force and electromagnetic torque are compared under different slot types. Simulation result shows the peer slot is best. Experiments on a 60kW PM Motor with Halbach Structure and peer slot is in good agreement with simulation.
\end{abstract}

Keywords: PM motor; stator slot-type; air-gap magnetic flux density; torque-ripple

\section{INTRODUCTION}

Increasing the air-gap flux density of motor is effective in reducing motor size and increasing energy density ${ }^{[1]}$. Generally there are two approaches. One is to choose materials with high residual magnetic flux density. The other is to change the arrangement of magnetic-steel structure. Researcher Klaus Halbach from Lawrence Berkeley National Lab in the U.S. created the Halbach array in 1979 , which provided an excellent solution to the second approach.

The original study on Halbach array started with the development of propeller integration system. Common PM motor can't meet the needs of propeller integration system because of the limits to motor size, weight and air-gap width. As the Halbach array has optimal effect on rotor poles, the requirements of propeller integration PM motor can be properly adapted by using this array. As a result, the development of propeller integration motor is greatly promoted. Consequently, Halbach arrays are widely used in different fields, such as high-speed motor, servo motor and medical science.

A large amount of theoretical and application study has been made on Halbach array. References [2] and [3] built Halbach array magnetic field model by using magneto-motive force method, under the condition of unlimited length of PM structure. Reference [4] presented that the thickness of PM structure has apparent influence on air-gap flux density. Reference [5] studied motor dynamic procedures by using magnetic circuit method. Reference [6] put forward that for out-rotor Halbach motors the proportion of inner diameter and outer diameter is an important factor affecting air-gap flux density. Reference [7] compared the performances

*Corresponding author: gagaga92@163.com of traditional spherical motors and Halbach spherical motors by using FEM method. Reference [8] superposed magnetic fields produce by single PM steels, but calculation amount is too big. All these studies have acquired fine academic achievements, but few researches have concerned the relationship between the stator of PM motor and air-gap flux density. In fact, the structure of stator will apparently influence the air-gap flux density.

According to the characteristics of Halbach array, the intensifying effect of the Halbach array on magnetic flux density of air-gap is analyzed, and the electromagnetic field of PM motor is calculated. By using FEM method, the magnetic flux density of air-gap, back phase electromotive force and electromagnetic torque are compared under different slot-types.

\section{HALBACH ARRAY}

\subsection{Halbach structure}

In general, radial or tangential structure is used on a PM motor. Halbach array combines two structures together. The auxiliary tangential magnet can weaken magnetic flux leakage between poles, and compensate main pole flux because of superposition. As a result of combination, the magnetic field intensity of one side is very strong while that of the other side is very weak, as is shown in Figure 1. By making use of this feature, the dynamic control characteristics of motor will be increased or the air-gap width can be increased without decreasing the amplitude of air-gap flux density, which will certainly improve the reliability of the motor. 


\section{MATEC Web of Conferences}

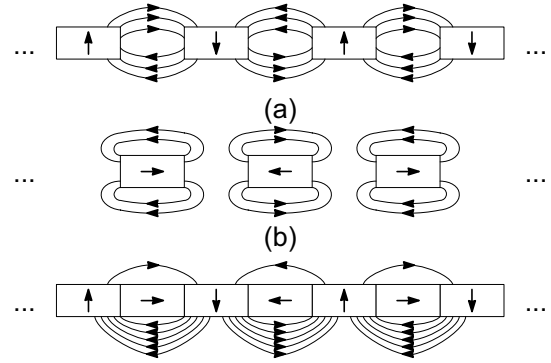

(c)

(a) Radial structure (b) Tangential structure (c) Halbach Array

Figure 1. Halbach array structure

\subsection{Features of Halbach array}

Halbach array has many excellent characteristics:

(1) Halbach array may produce ideal sinusoidal distributed magnetic field in space, which can apparently reduce cogging-torque.

(2) Halbach structure has strong magnetic field on one side and weak magnetic field on the other side. This may help to improve air-gap flux density and power density, to reduce size and yoke flux.

(3) High magnetic energy density can allow the motor to have wide air-gap. Halbach array can increase motor efficiency and reduce open circuit loss.

(4) By using Halbach array, torque ripple can be decreased and the requirements of the motor for the bearing can also be decreased.

Figure 2 shows the composition of magnetic force line, which intuitively reflects the optimizing effect of Halbach structure on air-gap.

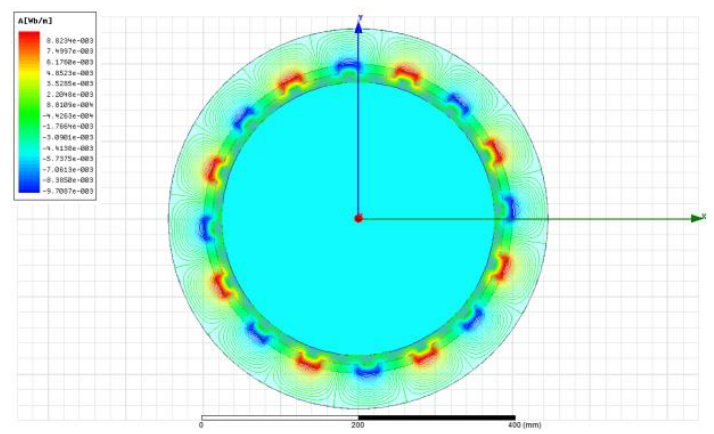

Figure 2. Halbach motor air-gap magnetic field

\section{MAGNETIC FIELD ANALYSIS OF HALBACH MOTOR}

\subsection{Magnetic circuit analysis for PM motor}

During the operating process, magnetic force $\mathrm{Fm}$ and flux $\varphi_{m}$ in outer circuit produced by PM structure is variable. PM structure is equivalent to a parallel connection source including a constant flux source $\varphi_{r}$ and a constant magnetic conductance $\wedge 0$, as is shown in Figure 3.

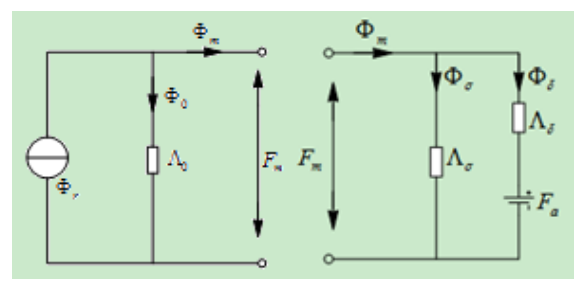

(a)

(b)

Figure 3. PM motor equivalent magnetic circuit

In Figure 3, $\varphi_{m}$ is the total flux per pole $(\mathrm{Wb})$ provided from PM structure to outer magnetic circuit; $\varphi_{r}$ is virtual intrinsic flux, which is a constant under given performance and size of PM structure; $\varphi_{0}$ is virtual leakage flux of PM, $\wedge 0$ is the inner magnetic conductance $(\mathrm{H})$ of $\mathrm{PM}$, which is also a constant under given performance and size of PM structure; Fm is the outer magnetic circuit magneto-motive force produced by both PM ends of each pair of poles(A).

The total flux $\varphi_{m}$ can be divided into two parts: one is main flux (air-gap flux per pole) $\varphi \delta$, and the other is leakage flux $\varphi_{\sigma}$. Accordingly, outer magnetic circuit can be divided into main circuit and leakage circuit, and the corresponding magnetic conductance are main conductance $\Lambda \mathrm{m}$ and leakage conductance $\wedge \sigma$. Assuming that when the motor operates, armature magneto-motive force Fm produced by every pair of poles' circuit contains both direct axis and quadrature axis magneto-motive force, the equivalent circuit is shown in Figure 3. The value of $F m$ is positive during demagnetization, otherwise negative. The whole equivalent magnetic circuit is the combination of Figure 3(a), (b).

\subsection{Electromagnetic analysis for PM motor}

Considering the complexity in the real manufacturing process, a discrete $90^{\circ}$ Halbach structure is often used in engineering. According to the research, taking 2:1 as the proportion of radial and tangential PM size can properly trade off between air-gap flux density, approximate sinusoidal distribution, and limits of manufacturing process ${ }^{[9]}$. In order to reduce the calculation workload, the common rectangular coordinate system should be changed ${ }^{[10]}$. Figure 4 shows the calculation model of the motor magnetic field, where $R r$ is inner diameter of PM structure; $R m$ is outer diameter of PM structure; $R s$ is inner diameter of the stator; $\tau_{m p}$ is pole distance; $\tau_{m r}$ is the arc length of radial magnet; $\tau_{m} \theta$ is the arc length of tangential magnet; $\beta$ is the ratio coefficient, i.e., $\tau_{m r} / \tau_{m} \theta$. 
ICETA 2015

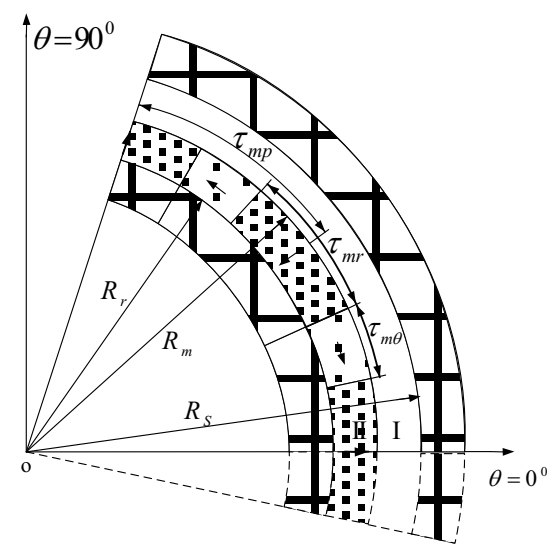

Figure $4.90^{\circ}$ Halbach motor structure

$\nabla \cdot \hat{\vec{B}}=0$ ding to the principle of flux continuity $\nabla \cdot \vec{B}=0$, the basic magnetic field equation in area I and II can be deducted

$\nabla^{2} \varphi=\frac{\partial^{2} \varphi}{\partial r^{2}}+\frac{\partial \varphi}{r \partial r}+\frac{\partial^{2} \varphi}{r^{2} \partial \theta^{2}}=0$

$\nabla^{2} \varphi_{\mathrm{II}}=\frac{\partial^{2} \varphi_{\mathrm{II}}}{\partial r^{2}}+\frac{\partial \varphi_{\mathrm{II}}}{r \partial r}+\frac{\partial^{2} \varphi_{\mathrm{II}}}{r^{2} \partial \theta^{2}}=\frac{\nabla \vec{M}}{\mu r}$

$\nabla \vec{M}=\frac{M r}{r}+\frac{\partial M r}{\partial r}+\frac{\partial M \theta}{r \partial \theta}$

In polar coordinates,

$\vec{M}=M r \vec{e}_{r}+M \vec{e}_{\theta}$

Where, $M$ is the residual magnetization of $\mathrm{PM} ; \mathrm{Mr}$ and $M \theta$ are respectively the radial and tangential component of $M$. The existence of $M$ makes the equation non-homogeneous.

In discrete Halbach array, the changes of $M r$ and $M \theta$ are not continuous. Fourier series should be used to decompose $M r$ and $M \theta$ so as to obtain the divergence of $M$. In practice, the calculation of air-gap magnetic field should consider variations produced by rated excitation in stator winding.

\section{ANALYSIS OF DIFFERENT SLOT-TYPE ON MAGNETIC FIELD OF HALBACH MOTOR}

According to the above-mentioned analysis, when the structures of stator and rotor are given, the air-gap flux is closely related to stator slot-type. Based on a 3-phase PM motor (basic parameters are shown in Table 1), the phase back electromotive force under rated rotating speed and the torque-ripple under rated operating state are compared between different slot types, i.e., open-square slot, peer slot and trapezoidal slot. The sizes of different slot types are in accordance with space factor.
Table 1. Motor parameter

\begin{tabular}{|c|c|c|c|}
\hline arameter & Value & Parameter & Value \\
\hline Rated power & $60 \mathrm{~kW}$ & $\begin{array}{l}\text { Number of turns in } \\
\text { series per phase }\end{array}$ & 88 \\
\hline \multicolumn{2}{|c|}{ Rated line voltage $380 \mathrm{~V}$} & Stator teeth distance & $13.4 \mathrm{~mm}$ \\
\hline air of poles & 8 & Rated phase current & $101 \mathrm{~A}$ \\
\hline umber of slots & 96 & Rated speed & $975 \mathrm{r} / \mathrm{min}$ \\
\hline \multicolumn{2}{|c|}{$\begin{array}{l}\text { Outer diameter of } 490 \mathrm{~mm} \\
\text { stator }\end{array}$} & space factor & 0.7484 \\
\hline \multicolumn{2}{|c|}{$\begin{array}{l}\text { Inner diameter of } 410 \mathrm{~mm} \\
\text { stator }\end{array}$} & Stato & $11.3 \mathrm{~mm}$ \\
\hline \multicolumn{2}{|c|}{$\begin{array}{l}\text { Outer diameter of } 398 \mathrm{~mm} \\
\text { rotor }\end{array}$} & Polar distance & $80.5 \mathrm{~mm}$ \\
\hline Air-gap width & $6 \mathrm{~mm}$ & Pole-arc coefficient & 0.70 \\
\hline $\begin{array}{l}\text { Conductors per } \\
\text { slot }\end{array}$ & 22 & Paraller branches & 4 \\
\hline Core length & $115 \mathrm{~mm}$ & PM 1 & $11 \mathrm{~mm}$ \\
\hline Wind & 6 & Stacking factor & 0.93 \\
\hline $\begin{array}{l}\text { Stator DC re- } \\
\text { sistance }\end{array}$ & \multicolumn{2}{|c|}{$0.068 \mathrm{ohmInsulating} \mathrm{paint} \mathrm{thick}$} & $0.08 \mathrm{~mm}$ \\
\hline
\end{tabular}

The stator uses double-layer winding; residual magnetic steel is $1.18 \mathrm{~T}$; the coercive is $891 \mathrm{~A} / \mathrm{m}$. The stator and rotor are built with silicon steel sheet, with type DW465_50.

The effective areas of three different slot types are of the same. Ansoft software is used for modeling and simulation. The specifications of different slot types, as is shown in Figure 5, are defined as follows:

(a) Open-square slot: bottom length $b=7.19 \mathrm{~mm}$, height between bottom line and slot notch $\mathrm{h}=28.7 \mathrm{~mm}$;

(b) Peer slot: notch height $\mathrm{h} 1=1 \mathrm{~mm}$, circular arc radius of stator notch $\mathrm{r} 1=3.6 \mathrm{~mm}$, height between stator inner diameter and bottom circle center $\mathrm{h} 2=18.62 \mathrm{~mm}$, stator notch width $\mathrm{b} 1=3.6 \mathrm{~mm}$, stator bottom circular arc radius $\mathrm{r} 2=5.48 \mathrm{~mm}$;

(c) Trapezoidal slot: notch height $\mathrm{h} 1=1 \mathrm{~mm}$, slot shoulder height $\mathrm{h} 2=2 \mathrm{~mm}$, height between shoulder and bottom $\mathrm{h} 3=25.7 \mathrm{~mm}$, notch width $\mathrm{b} 1=3.6 \mathrm{~mm}$, shoulder width $\mathrm{b} 2=7.2 \mathrm{~mm}$, slot bottom width $\mathrm{b} 3=8.026 \mathrm{~mm}$.

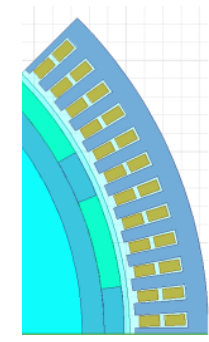

(a)

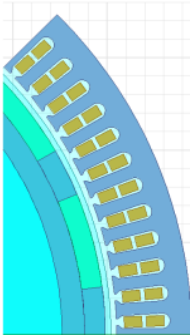

(b)

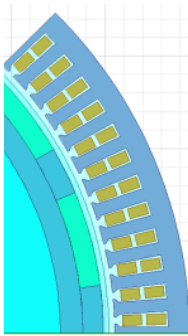

(c)
Figure 5. Slot size

\subsection{Wave form of air-gap flux}

According to Fourier transform of equation (1), the air-gap radial and tangential flux of PM motor can be described as follows: 
$B_{1 r}=-\sum_{n=1}^{\infty} \frac{B_{r}}{\Delta_{0}} \frac{n p}{1-n^{2} p^{2}} \Delta_{1}\left[\left(\frac{r}{R_{s}}\right)^{n p-1}\left(\frac{R_{m}}{R_{s}}\right)^{n p+1}+\left(\frac{R_{m}}{r}\right)^{n p+1}\right] \cos (n p \theta)$

$B_{1 \theta}=\sum_{n=1}^{\infty} \frac{B_{r}}{\Delta_{0}} \frac{n p}{1-n^{2} p^{2}} \Delta_{\mathrm{l}}\left[\left(\frac{r}{R_{s}}\right)^{n p-1}\left(\frac{R_{m}}{R_{s}}\right)^{n p+1}-\left(\frac{R_{m}}{r}\right)^{n p+1}\right] \sin (n p \theta)$

Among three slot types, the peer slot and the trapezoidal slot has bigger radial component of air-gap flux, with a value of $0.77 \mathrm{~T}$, while that of the open-square slot is smaller, which can be seen in Figure 6 .

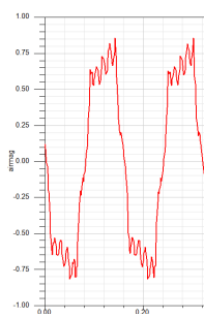

(a)

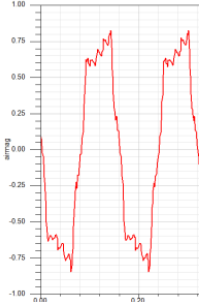

(b)

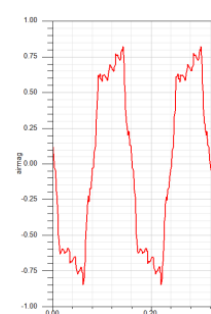

(c)
Figure 6. Air-gap radial flux

\subsection{Phase back electromotive force}

The phase back electromotive force E1 in stator winding is inducted by no-load air-gap fundamental flux produced by PM structure.

$$
E_{1}=4.44 f N \phi K d p
$$

Where, $\mathrm{f}$ is frequency; $\mathrm{N}$ is number of turns in series per phase; $\varphi$ is flux; Kdp is winding coefficient. E1 significantly affects the steady state performance of motor. An appropriate design may raise the working efficient and reduce the temperature of motor.

Open-square slot (a): the effective value of phase back electromotive force is $225.66 \mathrm{~V}$, and the effective value of $130 \mathrm{~Hz}$ fundamental wave is $224.83 \mathrm{~V}$. Peer slot (b): the effective value of phase back electromotive force is 233.41 , and the effective value of $130 \mathrm{~Hz}$ fundamental wave is $232.41 \mathrm{~V}$. Trapezoidal slot(c): the effective value of back electromotive force is $229.75 \mathrm{~V}$ and the effective value of $130 \mathrm{~Hz}$ fundamental wave is 228.97V, as is shown in Figure 7.

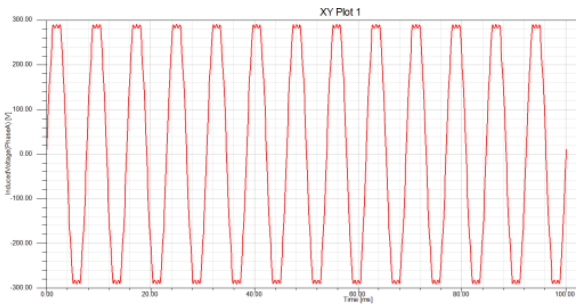

(a)

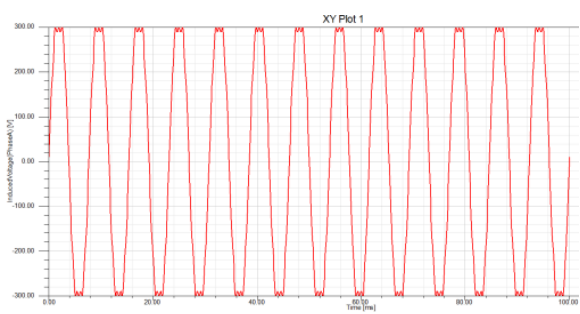

(b)

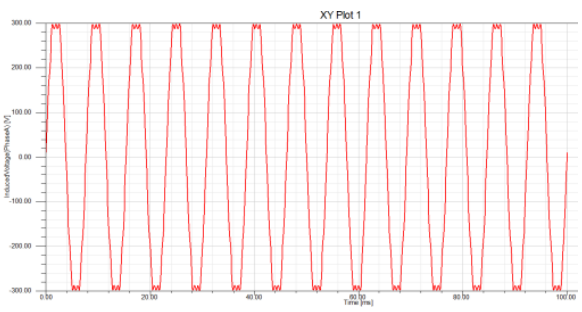

(c)

Figure 7. Phase back electromotive force

The following data is acquired from the results of FFT:

Open-square slot (a): fundamental amplitude of back electromotive force is $317.6 \mathrm{~V}$; amplitude of third harmonic wave is $24.9 \mathrm{~V}$. Peer slot (b): fundamental amplitude of back electromotive force is $328.3 \mathrm{~V}$; amplitude of third harmonic wave is $27.5 \mathrm{~V}$. Trapezoidal slot (c): fundamental amplitude of back electromotive force is $323.4 \mathrm{~V}$; amplitude of third harmonic wave is $22.9 \mathrm{~V}$, as is shown in Figure 8.

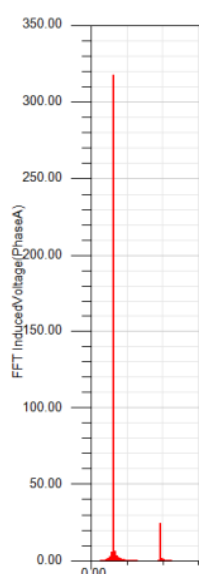

(a)

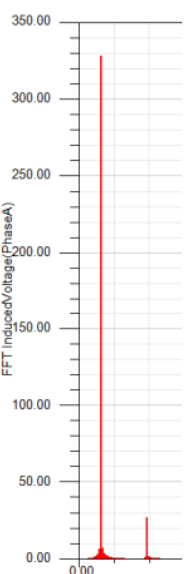

(b)

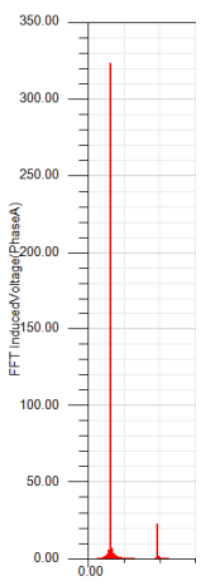

(c)
Figure 8. Phase back electromotive force FFT

\subsection{Electromagnetic torque}

In the two-dimension magnetic field, the density of tangential electromagnetic force working on motor 
ICETA 2015

stator and rotor can be described as

$$
f_{t}=\frac{B_{n} B_{t}}{\mu_{0}}
$$

Electromagnetic torque is produced by tangential force. If we do integral around a circle with radius $r$, the electromagnetic torque is

$$
T_{e m}=\frac{L_{e f} \oint r^{2} B_{r} B \theta d \theta}{\mu_{0}}
$$

Where, $r$ is the radius of air-gap circle; $B r$ is the radial component of air-gap flux at radius $r ; B \theta$ is the corresponding tangential component. In the circular integral, if radius is defined, then $r$ is a constant. Lef is calculating length of armature; $\mu 0$ is the magnetic conductivity in space.

After adding rated excitation on stator winding, the average torque value of open-square slot (a) is $718.1 \mathrm{~N} / \mathrm{m}$, with an error of $4.1 \%$. For the peer slot (b) the average is $703.7 \mathrm{~N} / \mathrm{m}$, with an error of $4.4 \%$. For the trapezoidal slot (c), the average is $698.9 \mathrm{~N} / \mathrm{m}$, with an error of $4.1 \%$, as is shown in Figure 9.

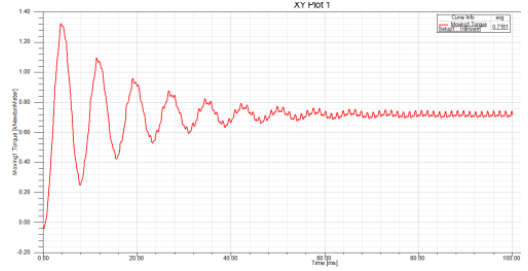

(a)

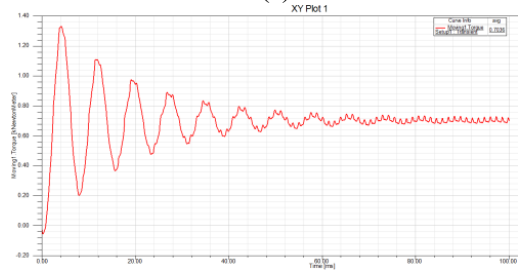

(b)

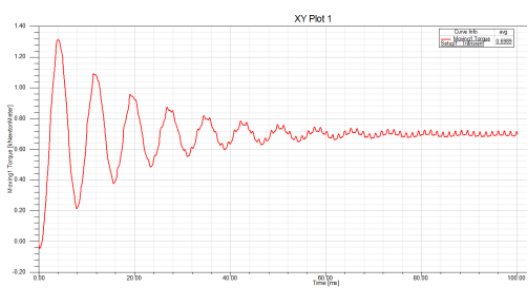

(c)

Figure 9. Rated operating torque

In conclusion, motors with different slot types have their own features. Back electromotive force harmonic wave, torque-ripple and transient time cannot be taken into account at the same time. In general, though the
PM motor with open-square slot has smaller torque-ripple, the PM motor with peer slot is better as a whole. Based on this, a Halbach PM motor with peer slot is independently developed for experiment and validation.

\section{EXPERIMENT}

A 60kW Halbach PM motor with peer slot is developed, as is shown in Figure 10. Drive the motor to its rated speed $975 \mathrm{rpm}$, measure the line back electromotive force of $a b$ and ac phases. The waveform is shown in Figure 10 (c). Its effective value are $401 \mathrm{~V}$ and $402 \mathrm{~V}$, which are in good agreement with the conversion results in the simulation and show the validity of simulation results.

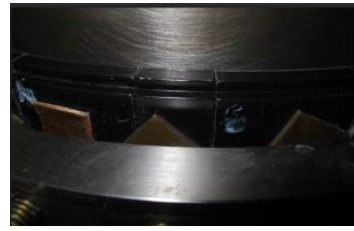

(a) Rotor PM

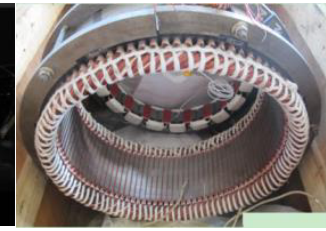

(b) Stator winding

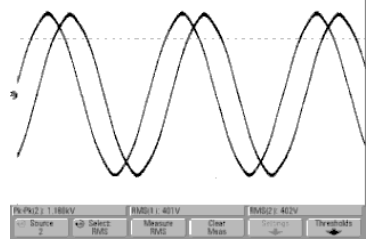

(c) Line back electromotive force

Figure 10. Experiment of $60 \mathrm{~kW}$ Halbach PM motor with peer slot

Table 2 shows the parameters measured for the motor under rated load operation. The parameter values of the first group are taken from room temperature operation, and those of the second group are from a steady temperature of the motor. Data show that the operation efficiency becomes bigger and power becomes smaller as temperature rises. In general, the performance doesn't change much.

Table 2. Experiment stats

\begin{tabular}{lll}
\hline Parameter & Value 1 & Value 2 \\
Frequency & $130 \mathrm{~Hz}$ & $130 \mathrm{~Hz}$ \\
Effective line volt & $401 \mathrm{~V}$ & $400 \mathrm{~V}$ \\
Effective phase current & $91.7 \mathrm{~A}$ & $91 \mathrm{~A}$ \\
Input power & $63.7 \mathrm{kw}$ & $63.3 \mathrm{kw}$ \\
Output power & $60 \mathrm{kw}$ & $59.7 \mathrm{kw}$ \\
Efficient & $94.19 \%$ & $94.31 \%$ \\
Power factor & 0.9996 & 0.9987 \\
Temperature & $25^{\circ} \mathrm{C}$ & $67^{\circ} \mathrm{C}$ \\
\hline
\end{tabular}




\section{MATEC Web of Conferences}

\section{CONCLUSION}

The features and advantages of Halbach array are analyzed, and the electromagnetic field of the motor is calculated. Halbach PM motors with different slot types are simulated and the following results are obtained:

(1) Motors with peer slot and trapezoidal slot have bigger radial component of air-gap flux amplitude, while that for open slot is smaller.

(2) The harmonics of phase back electromotive force mainly focus on third harmonic waves. The effective values of fundamental wave and whole wave for back electromotive force under open circuit are almost of the same for a single slot type. But the fundamental amplitudes for different slot types are obviously different. The peer slot has biggest fundamental amplitude, with a value of $328.3 \mathrm{~V}$, while the second is open slot, with a value of $323.4 \mathrm{~V}$. For the third harmonics, the open slot and the trapezoidal slot have similar values, and the peer slot is bigger, with a value of $27.5 \mathrm{~V}$.

(3) Each slot type has similar transient times, but the open slot comes to steady state $20 \mathrm{~ms}$ faster than other slot types. The average torques for motors with different slot types are close, with the open-square slot a little bigger, with a value of $718 \mathrm{~N} / \mathrm{m}$. Considering motor stability, the steady state errors of torque-ripples for three types of slot are all near $4 \%$, which is acceptable.

Motors with different slot types have different air-gap flux density, phase back electromotive force, torque. According to the results, peer-slot motor works better. Consequently, by using an independently developed $60 \mathrm{~kW}$ Halbach PM motor with peer-slot, experiment shows that the motor works stably.

\section{REFERENCES}

[1] Tang Ren-yuan. 1997. Modern Permanent Magnet Machines Theory and Design. Beijing: China Machine Press.

[2] Jin P. 2013. General analytical method for magnetic field analysis of Halbach magnet arrays based on magnetic scalar potential. Journal of Magnetics, 18(2): 95-104.

[3] Nguyen V H. 2013. A multi-axis compact positioner with a 6-coil platen moving over a superimposed Halbach magnet matrix.

[4] Chen Chuican, Ji Wenchen, Wang Aijun. 2010. The Effect of Magnet Structure Size on Halbach Array. Electric Switch Gear, 6(4): 11-13.

[5] Liu Y. 2011. Optimization of voice coil motor to en hance dynamic response based on an improved magnetic equivalent circuit model. IEEE Transactions on Magnetics, 47(9): 2247-2251.

[6] Johnson D, Pillary P, Malengret M. 2001. High speed PM motor with hybrid magnetic bearing for kinetic energy storage. IEEE Industry Applications Conference, (1): 57-63.

[7] Hongfeng Li, Changliang Xia, Peng Song. 2007. Magnetic field analysis of a Halbach array PM spherical mo- tor. IEEE International Conference on Automation and Logistics, Shandong, 2019-2023. X

[8] Ham C. 2013. Study of a Hybrid magnet array for an electrodynamic magnet control. Journal of Magnetics, 18(3): 370-374. Z

[9] Li Geng, Qiao Mingzhong, Liang Jinghui, Huang Liuwei. 2012. Optimum Design for Halbach Structure Applying Permanent Magnet Motor. Electric Machines \& Control Application, 39(1): 6-10.

[10]Dwari S, Parsa L. 2011. Design of Halbach array based permanent magnet motors with high acceleration. IEEE Transactions on Industrial Electronics, 58(9): 3768-3775.

[11]Zhu Z Q, Xia Z P, Atallah K. 2002. Comparison of Halbach magnetized brushless machines having discrete magnet segments of single ring magnet. IEEE Transactions on Magnetics, (9): 2997-2999. 